1 Universidade Estadual do Rio de Janeiro (Uerj), Instituto de Medicina Social (IMS) - Rio de Janeiro (RJ), Brasil.

2 Fundação Oswaldo Cruz (Fiocruz), Instituto Fernandes Figueira (IFF) Rio de Janeiro (RJ), Brasil. cbonan@globo.com

\section{Trajetória de uma intelectual, das ciências sociais à saúde coletiva: entrevista com Maria Andrea Loyola}

\author{
The trajectory of an intellectual, from social sciences to collective \\ health: interview with Maria Andrea Loyola
}

Maria Andrea Loyola', Claudia Bonan², Ivia Maksud²

DOI: 10.1590/0103-11042021E118

\begin{abstract}
MARIA ANDREA LOYOLA é socióloga e professora emérita do Instituto de Medicina Social (IMS) da Universidade do Estado do Rio de Janeiro (Uerj). A entrevista foi realizada no dia 30 de outubro de 2019, como atividade de encerramento da disciplina 'Tópicos Especiais em Ciências Sociais e Humanas em Saúde: Leituras de Pierre Bourdieu', ministrada pelas professoras Claudia Bonan e Ivia Maksud, no Programa de Pós-Graduação em Saúde da Criança e da Mulher do Instituto Fernandes Figueira/Fundação Oswaldo Cruz (IFF/Fiocruz). Na ocasião, para uma plateia de docentes e discentes, Maria Andrea nos falou sobre sua trajetória acadêmica, sobre o pensamento de Pierre Bourdieu, com quem teve intenso intercambio intelectual, sobre as ciências sociais no campo da saúde coletiva e, ainda, nos proporcionou um precioso testemunho histórico da saga de mulheres no mundo das ciências, na segunda metade do século XX. A entrevista foi gravada e transcrita e, em seguida, editada a seis mãos.
\end{abstract}

IVIA MAKSUD: Poderia nos contar um pouco sobre a sua trajetória? Para aludir à proposta do último livro do Pierre Bourdieu, como seria o 'esboço da sua autoanálise'?

MARIA ANDREA LOYOLA: Em primeiro lugar, obrigada pelo interesse de vocês em minha trajetória intelectual. Ela é muito menos o resultado de uma autoanálise do que de uma série de circunstâncias às quais fui respondendo mais sensitiva e impulsivamente do que a partir de uma reflexão racional. Ela tem início quando, no final dos anos 1950, ingressei no Curso de Ciências Sociais da Universidade Federal de Juiz de Fora, naquela época ainda Faculdade de Filosofia e Letras, fundada por um grupo de intelectuais católicos. E, em consequência, os autores estudados eram todos da corrente humanista católica: Bernanos, Santo Agostinho, Jacques Maritain, entre outros no gênero. Curiosamente, foi minha profunda ignorância dos autores clássicos da sociologia que me permitiram ser aprovada para um Curso de Especialização em Antropologia Social, com apenas três vagas e 25 candidatos, oferecido pelo Museu Nacional da UFRJ. A seleção incluía uma prova baseada num tema sorteado e uma entrevista, durante a qual fui perguntada se havia lido Durkheim, Weber, Lévi-Strauss, entre outros, e minhas respostas eram sistematicamente 'não'. Fui aprovada porque fui considerada uma 'folha em branco,' ideal para a nova formação e, principalmente, por revelar sensibilidade sociológica na minha prova, sobre o tema da diferença geracional, a qual fiz tomando como exemplo minha própria vida e a de minha mãe. Na verdade, fiz aquele concurso porque incluía uma bolsa de estudos, com a qual poderia viver no Rio de Janeiro e cursar Belas Artes, carreira com que sonhava na época 
e minha família não aprovava (carreira, ou melhor, hobby, ao qual finalmente pude me dedicar depois de aposentada). Mas esse curso, posso dizer, foi um marco em minha vida. Primeiramente, por seu alto nível: era um curso em tempo integral, com uma vasta bibliografia e excelentes professores, como Roberto Cardoso de Oliveira, Luís de Castro Faria, Roque Laraia e Roberto Da Matta, Alcida Ramos e outros estrangeiros que passaram por lá. Em segundo lugar, porque a leitura das diversas monografias descrevendo a cultura e modo de vida de outros povos, relativizaram as crenças em que fui formada e contribuíram para me libertar das rígidas normas da educação mineira daquele período. Depois desse curso, fiz uma Especialização em Arqueologia, também no Museu Nacional, e passei três meses no Paraná explorando sambaquis. Adorei aquela experiência, mas também me convenci que preferia explorar pessoas vivas e a cultura contemporânea do que aquele passado remoto. Com o golpe de 1964, voltei para Juiz de Fora.

Além de terem aberto um Curso de Licenciatura em Ciências Sociais, que eu não havia cursado, o ambiente político no Rio começou a ficar muito pesado. Embora eu nunca tenha pertencido a nenhum partido político, eu era simpatizante e muito próxima dos movimentos de esquerda, inclusive de alguns membros daquele grupo da Dilma, que quando vinham de São Paulo se hospedavam no apartamento quarto e sala que eu dividia com cinco amigas, num bairro mal afamado do Rio de Janeiro, que era o que podíamos pagar.

Em Juiz de Fora, fui convidada para dar aula de sociologia na já então UFJF, e, também, de antropologia na UFMG, em Belo Horizonte, em substituição a um colega que fez o curso comigo no Museu e que havia sido preso. Ia e voltava de ônibus toda semana durante dois anos. Foi uma época de muito trabalho, pois, além disso, passei a trabalhar como socióloga em uma fábrica de tecidos de Juiz de Fora, com uma antropóloga, Rosa
Stepanenko. Coisa raríssima, um empresário abrir a fábrica para sociólogos estudarem os operários. Tinha um conflito lá na tecelagem entre os supervisores e os operários, e o dono nos contratou para ver o que estava ocorrendo. Colhemos um material fantástico que usei em minha tese de doutorado; e, posteriormente, com novas entrevistas realizadas com sindicalistas locais, deu origem a meu primeiro livro, 'Os sindicatos e $\mathrm{PTB}^{\mathbf{1}}$ onde analisei o movimento operário em Minas Gerais. Nesse meio tempo, ocorreu uma história engraçada: como meu pai era general, o jornal 'O Globo' achou que eu era uma pessoa capaz de ter acesso aos processos políticos que corriam na Quarta Região Militar, sediada em Juiz de Fora, e me convidou para ser correspondente local. De fato, tive acesso a muitos processos, todos eles sem nenhum fundamento, baseados apenas em ouvir falar, e enviava cópia para o jornal, mas também para os meus colegas de esquerda. Até ajudei a tirar alguns deles da cadeia. Eles prendiam com base em qualquer coisa. Em geral, por indicação de alguém que queria ficar no lugar do denunciado. Tinham uns oficiais jovens que queriam tirar o governador de Goiás e me pressionavam para escrever falando que ele pretendia envenenar a água da cidade. Marcavam encontro por telefone e depois mudavam de lugar, como se estivessem sendo permanentemente seguidos. De fato, estavam em meio a uma conspiração forjada por eles. Chegaram a me oferecer para escrever uma coluna. Mas, percebendo que queriam me usar, agradeci. Claro que minha carreira como jornalista não durou mais do que dois meses. Outra carreira breve e voluntariamente interrompida foi minha carreira de bancária. Isso aconteceu a pedido de uma amiga insegura que me solicitou para acompanhá-la em um concurso para o Banco Real. Tendo passado neste concurso, trabalhei seis meses como correntista, naquelas máquinas de calcular enormes movidas a manivela. Foi um período muito sofrido, mas que me tornou uma pessoa que até hoje faz contas de cabeça. 
CLAUDIA BONAN: Além de professora, jornalista e bancária, você também teve uma experiência política nos anos 1960, não é?

MARIA ANDREA LOYOLA: Em 1966, Itamar Franco, então um jovem engenheiro de 32 anos, candidatou-se à Prefeitura de Juiz de Fora pelo PTB (Partido Trabalhista Brasileiro). Eu e Alexis Stepanenko, um também jovem sociólogo formado em São Paulo, então lecionando sociologia na Escola de Serviço Social, resolvemos fazer uma pesquisa de opinião eleitoral (talvez a primeira no Brasil). Arrumamos dois caminhões, convocamos os alunos de várias faculdades e fomos para os bairros mais populares de Juiz de Fora indagando sobre a intenção de voto de seus habitantes. Itamar perdia de forma arrasadora, e o outro candidato do PSD (Partido Social Democrático), partido no poder há anos, ganhava folgadamente. Ficamos na dúvida se publicávamos ou não os resultados, acabamos publicando. Os direitistas, sentindo-se vitoriosos, relaxaram; e Itamar concentrou sua campanha onde a pesquisa havia revelado que ele perdia. Acabou se elegendo e se tornou o mais jovem prefeito de Juiz de Fora e com uma equipe formada também por jovens, que ficou conhecida como as 'crianças no poder'. Isso porque ele não tinha com quem governar. Seu governo era permanentemente ameaçado, tanto pelos velhos políticos quanto pelos militares. Estávamos em plena ditadura. Por causa disso, ele me pediu para ser Chefe de Gabinete, 'até conseguir outra pessoa'. Eu não tinha a menor noção do que significava isso e só percebi a real dimensão desse cargo quando, durante uma viagem de Itamar à Alemanha, a Câmara Municipal pediu o impeachment dele, por causa de uma agenda que eu havia construído e que, segundo eles, os impediam de ter acesso ao prefeito. Na verdade, a agenda elaborada por mim reservava três tardes de livre acesso dos vereadores ao gabinete de Itamar, limitando a verdadeira invasão que eles promoviam, querendo ser atendidos sem dia nem hora, tornando muito difícil o prefeito trabalhar. Descobri então que era a segunda autoridade local e que, na ausência do prefeito, era eu que respondia e que tinha de resolver o problema do impeachment (o vice-prefeito era do PSD e ainda não havia assumido). Não me lembro direito como me saí, mas acho que foi convocando a imprensa e acusando os vereadores de não deixar o prefeito trabalhar para a cidade. Uma 'mulher' de 26 anos com tanta autoridade não era aceitável para uma cidade ainda provinciana e conservadora como Juiz de Fora naquela época.

IVIA MAKSUD: Você sofreu represálias ou ameaças por isso?

MARIA ANDREA LOYOLA: A conta veio na forma de um processo instaurado pelo Conselho da Faculdade e confirmado pela Reitoria. Retirando temas descontextualizados de um manual de antropologia do americano Kinsley Davis $^{2}$, me acusaram de pregar, referindo-se à teoria da evolução, que o homem vinha do macaco, o tabu do incesto, o infanticídio como forma de controle da natalidade, o comunismo, o tecnicismo e o amor livre. Este último porque, enquanto todas as moças consideradas 'de família', em oposição às 'largadas', só saiam acompanhadas por pais ou irmãos, eu e uma amiga frequentávamos os bares da cidade, acompanhadas de rapazes, considerados os melhores 'partidos' da cidade, o que causava muita inveja e nos divertia muito. Esse processo alimentou reportagens em vários jornais da cidade, até do Rio; e, como podem imaginar, fofocas sem fim. Hoje parece incrível uma coisa dessas, mas só para vocês terem uma ideia, um dos professores da universidade designados pela Reitoria para me interrogar me perguntou: "o incesto é um tabu?". Nitidamente eles não tinham a menor noção de nada. Eu disse incrível? É incrível mesmo, mas com Bolsonaro o criacionismo tornou-se política de Estado, e não duvido que pessoas sejam perseguidas por não pensarem dessa forma. 
Quando, em 1968, o Mestrado em Antropologia do Museu Nacional foi criado, me inscrevi e fui aprovada. Consegui então deixar a prefeitura, após cinco pedidos de demissão.

CLAUDIA BONAN: Maria Andréa, você viveu então os seus 20 anos na década de 1960, entre a docência em universidade pública, a pós-graduação, a gestão pública, a ciência e a política. Como foi uma mulher jovem viver tudo isso num período em que as portas da academia e da política ainda eram bastante fechadas para as mulheres? Que pioneirismo tiveram as gerações jovens mulheres dos anos 1960 ?

MARIA ANDREA LOYOLA: Acho que todas as mulheres de minha geração que se profissionalizaram tiveram que enfrentar e superar inúmeras barreiras. São verdadeiras arrombadoras de portas para elas próprias e para as gerações que se seguiram. Mesmo assim, como hoje é publicamente notório, a misoginia ainda é um fato, que tende, infelizmente, a se ampliar neste governo de Bolsonaro. Um triste retrocesso. No meu caso, o que já contei mostra em parte o que conquistei e o preço que paguei por isso. Quando meu processo na universidade se tornou público, as pessoas atravessavam a rua para não me encontrar. Teve uma época em que as únicas pessoas que me recebiam bem na cidade eram os boêmios dos bares que frequentava. Quando eu entrava num desses bares e o pianista tocava minha música preferida, esse gesto, confesso, enchia de calor meu coração. Mas, acho que em vez de me inibir, aquilo me dava força e me fazia seguir em frente. Acho também que a trajetória profissional dessas arrombadoras tem muito a ver com suas histórias de vida. No meu caso, por exemplo, o fato de ter perdido minha mãe quando ia fazer 5 anos de idade me obrigou a tornar-me uma guerreira, desde a primeira infância.

CLAUDIA BONAN: Nos conte um pouco sobre seu banimento e de professores de universidades públicas pelo Decreto-Lei n ${ }^{\circ}$ 477, em 1969 ?
MARIA ANDREA LOYOLA: Foi durante o mestrado que fui surpreendida com a notícia de que havia sido aposentada compulsoriamente pelo Decreto-Lei $n^{\circ} 477$, da Junta Militar. Fui avisada por um telefonema do Alexis que, em solidariedade a mim, naquele escabroso processo de Juiz de Fora, havia se demitido da universidade e se transferido para o Rio. Ele havia escutado a notícia na Hora do Brasil. Foi um período muito difícil, a toda hora ficávamos sabendo que um amigo ou conhecido havia 'caído', tinha sido preso. Foi o que aconteceu com a maioria dos professores compulsoriamente aposentados que não saíram do País. Alguns foram inclusive torturados. Escapei, em parte, graças ao professor Roberto Cardoso. Em meio àquele clima pós-AI-5, ele me chamou e disse: "Andréa você está chamando muita atenção para o Programa do Museu". Além de minha aposentadoria ter sido amplamente divulgada, eu era vizinha e amiga de Fernando Gabeira, desde a época de Juiz de Fora, e ele acabava de participar do sequestro do Embaixador Americano. $\mathrm{O}$ professor Roberto me disse: "Como uma das primeiras alunas do curso, você tem direito a uma bolsa da Fundação Ford para fazer doutorado nos Estados Unidos. Você escolhe: aceita essa bolsa ou vai desenvolver sua pesquisa no interior do Nordeste" - eu pretendia estudar a relação dos empresários nordestinos com a política. Escolhi a bolsa, mas com a condição de ir, não para os Estados Unidos, mas para a França. Não falava francês, mas conhecia a cultura francesa através do cinema. E para lá fui estudar com o professor Alain Touraine, na École des Hautes Études en Sciences Sociales (EHESS), que orientou meu doutorado. Ele trabalhava com sociologia do trabalho, e como eu tinha o material da pesquisa com os operários de Juiz de Fora, deu tudo certo.

IVIA MAKSUD: E o exílio, como ele marcou sua trajetória intelectual?

MARIA ANDREA LOYOLA: O exílio foi um período muito difícil, principalmente no 
início. Cheguei em 1969, em pleno início do inverno; e, além de não falar a língua, não conhecia ninguém. Levei uma carta de apresentação para a Aspásia Camargo, que também fazia doutorado com o Touraine, de quem me tornei grande amiga, inclusive dividimos um apartamento. Tornei-me também amiga de seu companheiro, o escultor Sergio Camargo; e, através dele, de vários artistas brasileiros, como Franz Kraisberg, Lygia Clarck, Rossini Perez; convivia com muitos artistas estrangeiros que moravam em Paris. $\mathrm{O}$ ambiente intelectual francês era efervescente. O marxismo dominava largamente as teorias sociológicas e antropológicas, e mesmo aqueles que tinham restrições ao excessivo economicismo de Marx - como Touraine, Aron, Bourdieu - eram obrigados a passar por ele. Tive a chance de frequentar os seminários de Levi-Strauss, Foucault, Aron, Althusser, Poulantzas e Balibar, destes últimos, na famosa Faculdade Marxista de Vincennes, reino do 'É proibido proibir', do movimento de maio de 1968. As discussões teóricas eram acaloradas e me fascinavam. No começo, você levava um susto, parecia que eles estavam brigando, mas era apenas a veemência de uma discussão absolutamente intelectual. Tive a oportunidade de fazer muitos amigos franceses e estrangeiros que estudavam em Paris e de viajar bastante pela Europa, Ásia e África. Aliás, foi na África que terminei de escrever minha tese de doutorado. $\mathrm{O}$ amigo que a estava traduzindo foi transferido para lecionar na Escola da Unesco do Togo, na África Ocidental, e o acompanhei. Tive a chance de conhecer vários países da África e vivi uma das experiências mais interessantes e marcantes de minha vida.

CLAUDIA BONAN: Havia diferenças importantes entre a academia francesa e a academia brasileira, no campo das ciências sociais, no que se refere à participação das mulheres na docência, na pesquisa, na gestão acadêmica? Em que o Brasil e a França se distanciavam e se aproximavam nesse aspecto? Que dificuldades mulheres brasileiras e francesas enfrentavam para fazer suas carreiras nas ciências naquela época?

MARIA ANDREA LOYOLA: Não sei muito fazer afirmações generalizadas sobre isso. Tinha muitas colegas mulheres, e na École havia muitas profissionais mulheres, embora poucas dirigindo laboratórios. As ciências sociais sempre foi uma área mais aberta às mulheres, mas, claro, para elas, as francesas, manter uma vida profissional não era fácil. O preconceito contra elas era menor do que no Brasil, mas aqui as profissionais contavam com empregadas, enquanto elas tinham, com pouca ajuda dos homens, de dar conta de todas as tarefas domésticas. Ainda hoje, as mulheres francesas têm uma vida bem dura. Uma das cooperações mais profícuas que mantive com a França, na área da saúde, foi com o Laboratório fundado e dirigido por uma mulher, Claudine Herzlich. Até hoje o IMS mantém uma colaboração estreita e muito produtiva com esse laboratório, o Centre d'Études et Recherches, Médecine et Santé (Cermes), coordenada por Marilena Correa e Maurice Cassier na área de inovação em saúde.

IVIA MAKSUD: Maria Andrea, você foi uma protagonista em áreas de estudo nas quais depois muitas mulheres no Brasil vieram a se destacar, como sociologia do trabalho, sociologia do corpo, estudos socioantropológicos da medicina popular. Como foi esse percurso, dos estudos do trabalho aos estudos da medicina popular e do corpo?

MARIA ANDREA LOYOLA: Em 1974, voltei para o Brasil para trabalhar na USP, convidada pelo Leôncio Martins Rodrigues, que havia me orientado no mestrado. Mas, como os professores compulsoriamente aposentados eram proibidos de trabalhar em instituições públicas, acabei indo lecionar na Pontifícia Universidade Católica (PUC) de São Paulo e trabalhar no Centro Brasileiro de Análise e Planejamento (Cebrap) - centro de pesquisa criado por ex-professores da USP para abrigar 
os professores aposentados. Foi assim que tive a oportunidade de ter como colegas, na PUC, Florestan Fernandes, Otavio Ianni, Vilmar Faria e Bolivar Lamounier, todos aposentados compulsoriamente; e, no Cebrap, Fernando Henrique Cardoso, Chico de Oliveira, Paul Singer, Arthur Giannotti e, principalmente, a demógrafa Elza Berquó. Trabalhei numa pesquisa fantástica, coordenada por ela, sobre a Reprodução Humana no Brasil, que descreve como se deu a transição demográfica no País, as transformações econômicas e sociais que a tornaram possível e as consequências demográficas, sociológicas e políticas que dela resultaram. Mas estas instituições, tanto a PUC como o Cebrap, viviam em constantes crises financeiras, e, assim, quando o José Luís Fiori me convidou para lecionar e participar de uma pesquisa em um instituto que estavam fundando na Uerj, o IMS, aceitei, mas sem deixar São Paulo. A Finep tinha dado um dinheiro para financiar o Instituto e suas pesquisas, e me pediram para fazer uma pesquisa sobre medicina popular.

A medicina popular era uma coisa atribuída ao folclore e estudada pelos folcloristas e acreditava-se que iria desaparecer com o tempo, à medida que a medicina científica avançasse. Mas minha hipótese era outra: como antropóloga que havia vivido na África, acreditava que as classes populares tinham uma visão do corpo diferente das classes altas e que, por isso, as práticas relativas à medicina popular não iam se extinguir. Elas podiam se enfraquecer, mas não terminar. Fui a campo, no final da década de 1970, com uma equipe de antropólogos para fazer pesquisa na Baixada Fluminense e encontramos, além de muita violência (como a que hoje chegou as comunidades do Rio), a medicina popular totalmente mergulhada na religião e, mais do que isso, objeto de uma violenta briga religiosa entre os pentecostais - que eram a Assembleia de Deus e a Universal se instalando -, vários terreiros de Umbanda e Candomblé, e a Igreja Católica, em que apenas uma irmãzinha italiana respondia pela Igreja - o padre aparecia de vez em quando. Para estudarmos teórica e historicamente as religiões presentes na área, fizemos uma divisão do trabalho: eu fiquei com o catolicismo; a Delma [Pessanha Neves], com o protestantismo; e a Zélia [de Lossio Zeiblitz], com o espiritismo. O sagrado não é uma coisa que você se apropria diretamente. Nas igrejas pentecostais e neopentecostais, o pastor arruma um terno, uma garagem, faz um mini estágio, vira pastor e começa a pregar e a interpretar a bíblia. Geralmente, interpreta em função dos seus vizinhos, de acordo com a cultura que ele compartilha com a comunidade. Quais são as religiões que competem diretamente com os evangélicos nas classes populares? Umbanda e Candomblé, que também se enraízam na cultura popular. Não é a Igreja Católica. Ao contrário, ela se afastou dos rituais tradicionais, como as procissões, por exemplo, e incorporou o ethos ascético das classes médias. No campo que selecionamos para estudo, o Bairro de Santa Rita, em Nova Iguaçu, a disputa entre os neopentecostais e o espiritismo popular de origem africana se dava em torno da oferta por cura de doenças. E para lidar com essa oferta e a presença, ainda que fraca no local, da medicina científica, faziam uma distinção entre 'doença espiritual' e 'doença material'. Doença material era enviada para o médico; doença espiritual ficava com os rezadores, egressos do catolicismo popular, com os pastores e com os pais e mães de santo. E tudo isso justificado por representações sobre o corpo, a saúde e a doença, em grande parte oriundas do catolicismo popular, que vigorou no Brasil desde a Colônia, e vigora ainda nas regiões rurais mais isoladas. Essa pesquisa produziu um material riquíssimo que encantou o Bourdieu, que me convidou para analisá-lo em seu laboratório, o Centre de Sociologie Européenne. O resultado desse trabalho foi publicado nos 'Actes de la Recherche en Sciences Sociales'3 e, pouco depois, foi publicado pelas edições da EHESS, no livro 'L'esprit et le corps'ㄱ. Depois foi traduzido e publicado no Brasil sob o título de 'Médicos e Curandeiros, Conflito Social e 
Saúde'5. Na verdade, quando fui para a França, no início dos anos 1980, com uma bolsa de seis meses do Cebrap, fui procurar Luc Boltanski, que trabalhava com Bourdieu, e tinha acabado de escrever um livro, que depois eu traduzi e publicamos no Brasil, sobre a relação do corpo com as classes sociais ${ }^{6}$. Como é fácil de perceber pelos que leem meu livro, os conceitos de campo e habitus foram fundamentais para organizar e analisar um material tão rico, vasto e complexo como o dessa pesquisa. $\mathrm{E}$ depois desse tempo, ficamos amigos; e ele me convidou várias vezes para dar aulas na EHESS e participar de trabalhos com o pessoal dele.

CLAUDIA BONAN: Você podia falar sobre Bourdieu como intelectual e figura pública de sua época?

MARIA ANDREA LOYOLA: O Bourdieu sempre foi assim meio arredio, sabe? Ele tinha um grupo muito dedicado a ele, mas não gostava de aparecer. Participava de movimentos políticos de esquerda, mas não de partidos políticos, como a maioria dos intelectuais da época que eram filiados ao partido comunista ou socialista. Para ele, a política era um objeto de estudo, e para fazer isso, precisava manter-se afastado, preservar a autonomia necessária ao trabalho intelectual. Tinha horror de aparecer na televisão, ao contrário, por exemplo, do Touraine, que vivia dando entrevistas. Eu não vejo problema nem em um estilo, nem em outro, mas para o Bourdieu, aquilo era um problema. Se vocês lerem 'Sobre a Televisão'7, vocês vão entender o porquê: para ele, os jornalistas colocam os intelectuais para legitimar o que eles querem dizer, e não o que o intelectual tem para dizer. Isso aconteceu comigo, no meu próprio trabalho. Na presidência da Capes, eu quase não dava mais entrevista, porque você falava uma coisa e eles publicavam outra, dizendo que foi você quem falou.

IVIA MAKSUD: Quais as contribuições teóricas, as inovações ao pensamento sociológico mais relevantes de Bourdieu, no seu ponto de vista?
MARIA ANDREA LOYOLA: Como eu disse, o campo intelectual francês - pelo menos o da sociologia e, em parte, da filosofia -, nos anos 1960/70, era totalmente dominado pela esquerda e pelo marxismo. Os menos marxistas eram exatamente Touraine e Bourdieu, mas mesmo assim, não havia nenhum intelectual na França que pudesse passar incólume por Marx. O domínio do marxismo era muito forte, como era no Brasil, quando, em 1974, eu voltei da França e fui dar aula na PUC. Para vocês terem uma ideia, como falo na entrevista que fiz com ele, os meus alunos da matéria que eu lecionava, Teoria Sociológica, se recusaram a ler Bourdieu, alegando que ele não dava conta da mudança. Mudar, para uma sociedade sem classes sociais, era a obsessão do momento, e uma leitura equivocada do livro 'A Reprodução', de Bourdieu ${ }^{8}$, levava a esse tipo de reação. Mas Bourdieu foi justamente a pessoa que enfrentou a noção de classe social do Marx. Por exemplo, como você responde à questão que me foi colocada uma vez por um aluno: "como é que você faz um questionário marxista?". Ninguém sabe responder, porque a proposta do Marx é absolutamente teórica, não é? Então, Bourdieu nos deu o que a gente pode chamar de trem de aterrissagem. Com o instrumental teórico e as ferramentas que ele criou, você consegue fazer com que a pesquisa dê conta das relações de classe, das diferenças sociais. Se as contribuições teóricas de Bourdieu podem ser úteis para analisar diferentes momentos da história e qualquer país é porque elas são justamente um conjunto de ferramentas para a pesquisa, e você não pode falar nada sobre qualquer assunto sem antes construir seu objeto e reforçá-lo pela pesquisa empírica. Eu não posso falar do Brasil, por exemplo, sem conhecer antes histórica e empiricamente sobre o que estou falando. Você não pega uma teoria sociológica e aplica a um determinado contexto, exatamente do jeito que ela foi criada para pensar um outro, totalmente diferente. Outra coisa que distingue Bourdieu dos marxistas é a maneira como ele trabalha com o conceito de classe. Se, em geral, todo 
mundo desenhava um triângulo para se referir à sociedade e à hierarquia social, Bourdieu as considera mais como um móbile, a maneira dos trabalhos de Calder, que, além de estarem constantemente mudando, variam de acordo com o contexto; ou seja, seu conceito de classe é mediado pela noção de campo e habitus. Outra coisa que, para mim, Bourdieu contribuiu é em relação ao economicismo da ideia marxista de cultura, ou superestrutura, que para os marxistas é determinada pela infraestrutura, pelas relações de produção. Bourdieu diz que não é uma coisa mecânica. Para ele, a premissa é verdadeira, mas mediada por uma estrutura simbólica, relativamente autônoma. É aí que vem a ideia de campo que funciona como um espaço de consenso e de conflito, em que as disputas, em geral, refletem posições de classe. Em outras palavras, as posições que as pessoas ocupam num determinado campo costumam ser homólogas àquelas que elas ocupam no espaço social: os dominantes no campo tendem a ser dominantes também no espaço social, e os dominados, idem. E o objeto dessa luta é pela hegemonia do no campo. Mas isso não é automático; tem que ser pesquisado e demonstrado. Vou dar o exemplo do campo político: o PT lutou para ter a hegemonia no campo político da esquerda, e até hoje a política do Lula ainda é nesse sentido. Então, no campo da esquerda, você compartilha ideias e objetivos, mas, ao mesmo tempo, você tem um permanente conflito para definir qual o grupo domina. Se você pegar o campo da academia, ou qualquer campo que você for estudar, vai ser assim - os campos também não são homogêneos, são heterogêneos.

CLÁUDIA Bonan: Como aconteceu a sua clássica entrevista com o Bourdieu? Como veio a ideia, como você processou? Desde o início a ideia era fazer um livro??

MARIA Andrea Loyola: Na época, eu era Sub-reitora de pós-graduação e pesquisa [2000-2003] da Uerj, e, ao organizar uma videoconferência com os Ministros de Educação do Brasil e da França, durante um encontro para comemorar os 20 anos do acordo de cooperação entre a França e o Brasil Capes/ Cofecub, que foi realizado na universidade, entrei em contato com a TV Universitária e com sua então diretora, Gabriela. Discutindo, tivemos a ideia de organizar um programa de entrevistas para mostrar as contribuições dos intelectuais acadêmicos para seu campo de estudo e ao mesmo tempo para a sociedade. Daí o título: 'Pensamento c Contemporâneo'. Naquela época, o livro do Bourdieu 'Sobre a Televisão'7 tinha acabado de ser traduzido para o português e difundido no Brasil, e achamos que seria extremamente oportuno começar por ele. Eu o convidei para uma entrevista, e ele aceitou imediatamente. Marcamos uma data, eu fiz as questões e mandei para ele, juntamente com um pequeno resumo sobre o que estava acontecendo no Brasil naquele momento, inclusive sobre o avanço dos pentecostais. Pierre Carles filmou uma parte da minha entrevista e reproduziu no filme que fez sobre Bourdieu, chamado A Sociologia é um esporte de combate, que é um filme enorme, com a trajetória do Bourdieu em conferências salas de aula, manifestações, que saiu logo antes ou depois de ele morrer em 2002. Até hoje, passa nas salas de cinema da França. Fiquei famosa entre os sociólogos franceses por isso [risos].

A entrevista comigo durou cinco horas, e ele ficou muito cansado. Acho que já estava ficando doente. Depois ele me convidou para almoçar. Foi a última vez que me encontrei com ele pessoalmente. Depois foi só por e-mail e telefone para discutir a edição da entrevista. A ideia do livro veio depois. $\mathrm{E}$ ao final, desse pequeno livro editado pela editora da Uerj (Eduerj) no que se tornou a Coleção 'Pensamento Contemporâneo', escrevi um pequeno texto introdutório sobre a Sociologia de Bourdieu: sua teoria, metodologia, principais conceitos e como usá-los, as críticas a ele dirigidas, sua biografia, bibliografia e obras traduzidas para o português. É um livrinho muito consultado. 
IVIA MAKSUD: Como o conceito de campo científico, tão caro para o Bourdieu, te ajudou a analisar o campo da saúde coletiva? Em dois artigos sobre o campo da saúde coletiva, você chama atenção para questões muito importantes como o produtivismo desenfreado, a perda de espaço da produção e da leitura de livros. Nesses textos, você também discutiu com firmeza a importância do Curso de Teoria Social e de Metodologia na Saúde Coletiva. Ao longo então dessa experiência de muitos anos, como vê hoje as ciências sociais na saúde coletiva?

MARIA ANDREA LOYOLA: Não sei se vocês leram meu artigo 'A saga das Ciências Sociais na Saúde Coletiva'10. Ali exatamente está a minha ideia de campo na saúde. Em geral, os estudiosos da área que usam a noção de campo, o usam apenas como um espaço multidisciplinar, ou seja, como um espaço que agrega várias disciplinas que têm por objeto o estudo da saúde. Eu o uso no sentido de Bourdieu, isto é, como um espaço de consenso e conflito. $\mathrm{Na}$ área da saúde coletiva, a hegemonia do campo foi, durante seus primórdios, da área de planejamento, o que tem muito a ver com o fato da então estreita relação entre a academia e a gestão de políticas públicas no interior do Estado, predominante na época. Com o tempo e a consolidação das principais políticas propostas para à atenção à saúde, notadamente a promulgação da Lei Orgânica do SUS, em 1990, a posição hegemônica no campo da saúde coletiva deslocou-se para a epidemiologia, como pode ser observado pelas posições que os epidemiólogos ocupam nas instancias de poder da área: postos de direção nas associações, de assessoria às agências de fomento, número de financiamentos e publicações etc. Mas isto tem a ver não somente com as disputas, em geral veladas, no campo da saúde coletiva, mas com as transformações econômicas, sociais, sobretudo tecnológicas, que ocorreram na sociedade, e principalmente no campo acadêmico. Neste campo, observamos um crescente domínio das ditas 'ciências duras' (física, química, biologia) que passam a impor seus paradigmas como referência, inclusive na avaliação dos cursos de pós-graduação pelas agências. Donde o já bastante criticado produtivismo quantitativista, que também aponto naquele artigo. A produção do conhecimento das ciências sociais é totalmente diferente do conhecimento das áreas duras. Por quê? Porque você não pode chegar aqui, fazer um experimento e transformá-lo em um artigo, como eu já vi, um artigo da física com apenas duas páginas: a primeira página contendo a o nome dos autores e a segunda o experimento em si. Nas ciências sociais, é preciso saber o que acontece lá atrás. Por exemplo, em um artigo que eu escrevi sobre a introdução dos genéricos no Brasil1", eu tive que ir lá para a década de 1950, e passar por todas as demais que se seguiram, para explicar o que estava acontecendo agora, no século XXI. Nesse campo, assim atualmente estruturado, as ciências sociais, que historicamente sempre ocuparam um lugar subalterno na hierarquia de prestígio das ciências (não por acaso, os médicos sempre foram dominantes na área), estão extremamente enfraquecidas. A epidemiologia, que era um método, virou uma disciplina, assim como o planejamento. As únicas disciplinas, de fato, da saúde coletiva eram as ciências sociais. As ciências sociais são, na verdade, o cerne da saúde coletiva. Como o próprio o nome indica, seu objeto é o aspecto coletivo da saúde, não o populacional, histórico objeto da demografia e da epidemiologia, desde a criação da saúde pública, no século XIX.

Como mostra Durkheim, o conceito de sociedade é diferente do de população. O social não constitui uma mera soma quantificável de indivíduos, mas algo que a transcende, pois existe antes e depois da mera existência dos indivíduos; é o que ele chamava de 'consciência coletiva' e que tem muito a ver com a ideia de habitus do Bourdieu, que ele define como o social incorporado nos indivíduos. É para a abordagem, nesses termos, desse lado coletivo da saúde que as ciências sociais, notadamente a sociologia, oferecem os 
instrumentos mais adequados. No começo da formação do campo da saúde coletiva, muitos nomes importantes, como as sociólogas Madel [Luz], a Cecília [Minayo], a Ana Canesqui e o Everardo em Campinas, o pessoal da Bahia, se destacaram por suas produções essencialmente críticas e sociais. Se você pegar a produção do período, nela predominavam os livros. Além dos sociólogos e antropólogos, os filósofos, como Roberto Machado, que levou Michel Foucault ao IMS, os psicanalistas, como Jurandir Freire e Joel Birman, os médicos, como o Hésio Cordeiro, os epidemiologistas, como Naomar, todos produziram livros com uma perspectiva crítica e social. O que eles liam? Marx, Foucault, Weber, Freud, Illich, entre muitos outros. Todos esses trabalhos, somados aos mais recentes, constituem o que eu considero a base da saúde coletiva como uma disciplina; o que vem gerando uma intensa discussão no campo. Muitos ainda se perguntam: o que é a saúde coletiva? Uma área, um campo, uma disciplina? A multidisciplinaridade que caracteriza a saúde coletiva constitui, de fato, um problema, sem contar suas relações com a saúde pública, a saúde preventiva, a saúde comunitária. Para mim, todas elas são, na verdade, denominações que enfatizam um determinado objeto, politicamente importante num determinado período (o aspecto público, a prevenção, a comunidade) e, num certo sentido, podem se somar e mesmo se equivaler à saúde coletiva, sem dúvida uma jabuticaba bem no estilo brasileiro, pois só existe no Brasil. Já se esforçaram mesmo para criar uma epistemologia capaz de abarcar as três vertentes da saúde coletiva: o planejamento, a epidemiologia e as ciências humanas. Eu, pessoalmente, não acredito nisso.

Ao contrário, acho que, cada vez mais, os epidemiólogos têm que se identificar como epidemiólogos; os sanitaristas, como sanitaristas; os economistas, como economistas; os historiadores, como historiadores; os psicanalistas, como psicanalistas, enfim: cada macaco no seu galho. O que os une é o objeto saúde coletiva: quanto melhor cada um fizer o seu trabalho de acordo com sua visão e metodologia especializada sobre um determinado tema referente à saúde, melhor será o resultado. Acho que todas as vertentes ou subáreas, independentemente de sua posição na hierarquia do campo, têm sua contribuição a dar. Uma vantagem que contribui para a riqueza da saúde coletiva é o fato de que você tem uma área teórica e uma área prática que se alimentam mutuamente.

Quando estava na Capes, eu pude ver o quanto o nosso o sistema de pós-graduação é heterogêneo e desigual: dentro e entre as áreas do conhecimento, dentro e entre as universidades, nas e entre as regiões do País. Para contornar essa diversidade, introduziram os algoritmos. Ao escantear e mesmo eliminar a metodologia qualitativa das ciências sociais, trabalha-se com a ideia de senso comum, enfraquecendo o lado crítico. O sistema de saúde cai aos pedaços, e a gente não consegue escrever, não consegue pensar a respeito!

E o pensamento crítico é fundamental para a saúde coletiva - mas só se chega a ele com ferramentas adequadas oferecidas pelas ciências sociais. Quanto ao que está acontecendo atualmente no País, eu não sei o que é pior ou mais destrutivo: a covid-19 ou o governo Bolsonaro.

CLÁUDIA BONAN: O Bourdieu disse, na entrevista que concedeu a você, a seguinte coisa: " $\mathrm{Eu}$ gostaria muito de defender um utopismo que fosse realista, mas para fazer isso é necessário conhecer o mundo. É preciso ser velho e jovem ao mesmo tempo". Disse também que nunca pertenceu a um grupo político, principalmente partido político, mas mesmo assim teve um enorme interesse político, coisa que considera fundamental para o intelectual. Ele diz: "O $\mathrm{so}$ ciólogo que cala ou ele não vê, não enxerga, não é competente, ou vê e se acomoda". Então hoje, mediante a conjuntura política e a atmosfera cultural que estamos vivendo, tão regressiva no que diz respeito às liberdades, aos direitos democráticos, à valorização da diversidade, às práticas da ciência e de educação, entre outras 
coisas, como você tem pensado o papel dos intelectuais progressistas?

MARIA ANDREA LOYOLA: Quando ele fala que você tem que ser velho e jovem ao mesmo tempo, ele quer dizer o seguinte: você tem que acreditar, você não pode perder sua crença em uma utopia, mas, ao mesmo tempo, ter maturidade para saber que você não pode agir apenas guiado pelo idealismo. Tem que pôr o pé no chão e encarar e conhecer a realidade que você quer mudar. Mesmo com a quilometragem que já rodei, eu não tenho uma fórmula para isso. Profissionalmente, acho que quando você faz sociologia, você tem que fazer sociologia, e não política. O que não te impede, entretanto, de ser politicamente estimulada. Mas se você for transformar a sua sociologia em política, você não faz sociologia. Eu acho que você tem que se restringir ao seu campo; se for ciência, você não pode deixar a política entrar ali; você tem que fazer ciência. Se você tenta fazer ciência com ativismo político, você não consegue fazer ciência. O que não significa ser neutro? Não existe neutralidade, mas é com a construção distanciada e reflexiva da realidade, inclusive da política, que você cria conhecimento. E como diz o próprio Bourdieu, "quanto mais científica você é, mais você contribui para a política".

IVIA MAKSUD: Você foi uma das intelectuais que introduziu com outros - como Moacir Palmeiras, Sérgio Miceli, Renato Ortiz - esse pensador no campo da saúde coletiva brasileira. Seu livro de entrevistas é uma obra de referência, é por ele que muitos estudantes de saúde coletiva se aproximam do Bourdieu. $\mathrm{O}$ que você pensa em relação aos usos dos conceitos de Bourdieu neste momento que muitos vão analisar como 'pós-moderno'?

MARIA ANDREA LOYOLA: Não gosto muito desse termo, pois não sei muito bem o que ele significa. Não estou dizendo que não existe uma 'pós-modernidade', mas que, de um modo geral, as pessoas utilizam modernidade e pós-modernidade como conceitos muito abrangentes e gerais, que, a meu ver, não são explicativos. Para Bourdieu, a relação entre realidade e história é muito forte, ao contrário de correntes 'pós-modernas' que enfatizam a relação realidade-narrativa. Considero que a realidade é histórica, é o produto de um passado que vai durar enquanto as instituições que sustentam esse passado perdurarem. $\mathrm{E}$ a realidade só se torna uma realidade precisa por meio de contornos e significados específicos, que são fruto de um processo histórico e social mais amplo. E, para isso, acho as ferramentas oferecidas pela sociologia de Bourdieu não as únicas, mas muito úteis para essa tarefa. Eu gostaria de abordar aqui as críticas que são feitas a Bourdieu. São críticas que, para mim, não se coadunam muito com a leitura que faço da obra dele. Seu conceito de habitus, por exemplo, é um conceito dinâmico, não é fixo como muitos o entendem. E, de fato, Bourdieu não é uma leitura fácil. Ele é um sociólogo da dominação, um sociólogo do poder, e não serve para os que não estão interessados nisso. $\mathrm{E}$ tem que ter metodologia. Infelizmente, a metodologia hoje é utilizada, se podemos dizer assim, sem método, isto é, sem rigor. Já avaliei um artigo colocado para publicação que categorizava respostas de apenas seis pessoas. Cada duas pessoas constituíam uma categoria. Infelizmente, convivemos hoje com pouco rigor científico. Não há mais metodologia. Não estão nem interessados no conhecimento; estão interessados na quantidade de publicação.

IVIA MAKSUD: No início da década de 1990, você organizou o livro 'AIDS e sexualidade: 0 ponto de vista das Ciências Humanas' ${ }^{\text {'2 }}$, uma das primeiras publicações a difundir essa temática no IMS e no campo da saúde coletiva, com um texto seu outros de autores relevantes, como Richard Parker, Sérgio Carrara, Michel Polak, Joel Birman, Marilena Correa e outros. Publicou também o livro 'A sexualidade nas Ciências Humanas' ${ }^{13}$. Sua geração deu e ainda dá uma contribuição fundamental ao estabelecimento dos temas do corpo, da sexualidade e 
da reprodução na saúde coletiva. Como você avalia a produção acumulada e vê os desafios atuais, colocados às novas gerações, para trabalhar essas temáticas?

MARIA ANDREA LOYOLA: Ainda bem que vocês me fizeram essa pergunta. Uma das vantagens das ciências sociais é que sua metodologia e bagagem conceitual te permitam trafegar por várias áreas. No meu caso, além da sociologia do trabalho, do corpo e, também, da demografia, como já abordado, minha grande preocupação intelectual, na qual investi muitos esforços de pesquisa, foi com a reprodução humana. Mais especificamente, com a relação entre a reprodução biológica e a reprodução social. E devo isso tanto à minha passagem pela demografia quanto à minha inserção na área médica. Nos anos 1980, ainda na França, Elza Berquó e Maria Coleta de Oliveira me procuraram e me propuseram ajudá-las a fundar o Núcleo de Estudos de População (Nepo), da Unicamp. Trabalhei por três anos nesse núcleo e o considero um período muito rico em minha trajetória intelectual. Com inquietação com o tema da reprodução biológica e social, em 1986, me engajei e coordenei uma pesquisa no Nepo sobre formas de união dos sexos e homogamia; fiz outra pesquisa, no IMS, sobre o amor, um texto que orientou todo o trabalho que desenvolvi sobre sexualidade - 'Sexualidade e Reprodução'14,15; e, posteriormente, com Marilena Corrêa, sobre reprodução assistida ${ }^{16-18}$. Minhas pesquisas sobre Aids me levaram também a relacionar a mundialmente famosa política do Ministério da Saúde à implantação dos medicamentos genéricos no Brasil, um típico trabalho de sociologia da saúde, realizado como parte de um grande projeto de cooperação com o Cermes, com financiamento francês. Não consigo avaliar em que direção e como as novas gerações vão abordar esses temas nem se vão se interessar por eles. De qualquer forma, deixo à disposição daqueles que quiserem trilhar caminhos semelhantes uma série de publicações que podem ser consultadas em meu
Curriculum Lattes e que lhes podem servir de ponto de partida. Fico devendo apenas a publicação de uma grande pesquisa realizada em 1990/91 no IMS, que alia, pela primeira vez, métodos qualitativos e quantitativos e aborda em três grupos sociais (metalúrgicos, bancários e profissionais liberais de diferentes idades) temas como amor, paixão, feminino, masculino, erotismo, casamento e filhos. Esse material foi usado em minha tese para obtenção do título de professora titular, mas, por uma série de circunstâncias, nunca 'saiu da gaveta'. Pretendo agora revê-lo para publicação, e, devido a sua extensão, na forma de um livro

CLAUDIA BONAN: Maria Andrea, a Capes, em seus 68 anos de existência, teve apenas três presidentes mulheres: a professora Suzana Gonçalves (1964-1966), a cientista social Eunice Durham (1990-1992 e 1995) e você, entre 1992-1994. Estudos mostram que a maioria expressiva dos cargos de reitor são ocupados por homens. Apenas recentemente mulheres foram eleitas como dirigentes de importantes instituições de ciência e ensino, como a UFRJ e a Fiocruz. Como você vê os obstáculos e as oportunidades para as mulheres nos níveis altos da gestão acadêmica? Podemos ver avanços nesse sentido?

MARIA ANDREA LOYOLA: Acho, sim, que houve avanços para as mulheres, como nas instituições que você mencionou. Mas acho que, em geral, eles ainda são bastante tímidos; e na Capes, ao que tudo indica, apenas cargos de diretoria para baixo estão abertos às mulheres. Depois de mim e das mulheres citadas, nenhuma mulher ocupou esse cargo, e apenas um cientista político, o Abílio Baeta Neves, esteve à frente desse importante órgão. Depois dele, apenas representantes das ciências duras, e agora das 'ciências duríssimas' - os militares - e dos religiosos. Acredito que se a Capes não tivesse sido dirigida por uma cientista social oriunda da saúde coletiva, essa área não teria sido autonomizada daquela da medicina. Não foi fácil enfrentar a hegemonia dos médicos, 
mas esse foi um dos bons resultados de minha trajetória profissional do qual muito me orgulho.

IVIA MAKSUD: Somos muito gratas por essa preciosa entrevista e por sua valiosa contribuição às ciências sociais e à saúde coletiva. Foi realmente um prazer conhecer mais a sua trajetória intelectual, e estamos certas de que sua leitura enriquecerá a formação dos pesquisadores do campo.

CLAUDIA BONAN: Eu também agradeço muito a sua generosidade de compartilhar com a gente a sua trajetória, tão inspiradora para aquelas e aqueles que se aventuram em fazer ciências sociais no campo da saúde coletiva.

\section{Colaboradoras}

Loyola MA (0000-0003-1442-9628)*, Bonan C (0000-0001-8695-6828)* e Maksud I (00000002-3465-151X)* colaboraram igualmente para concepção; planejamento; realização e edição da entrevista; e aprovaram a versão final do manuscrito.

\section{Referências}

1. Loyola MAR. Os sindicatos e o PTB. Petrópolis: Vozes; 1980.

2. Davis K. A Sociedade Humana. Rio de Janeiro: Fundo de Cultura; 1964.

3. Loyola MAR. Cure des corps et cure des âmes. Les rapports entre les médecines et les religion dans la banlieue de Rio. Actes de la recherche en scien. soc.1982; 43(1):3-45.

4. Loyola MAR. L'esprit et le corps. Des thérapeutiques populaires dans la banlieue de Rio. Paris: éditions de la Maison de Sciences de l'homme; 1983.

5. Loyola MAR. Médicos e Curandeiros: conflitos sociais e saúde. São Paulo: DIFEL; 1984.
6. Loyola MAR. As classes sociais e o corpo. Rio de Janeiro: GRAAL; 1980.

7. Bourdieu P. Sobre a Televisão. São Paulo: Zahar; 1996.

8. Bourdieu P. A Reprodução. Elementos para uma Teoria do Sistema de Ensino. Petrópolis: Vozes; 1970.

9. Loyola MAR, editora. Pierre Bourdieu. Entrevistado por Maria Andréa Loyola. Coleção Pensamento Contemporâneo. Rio de Janeiro: EdUERJ; 1999.

10. Loyola MAR. A Saga das Ciências Sociais na área da Saúde Coletiva: elementos para reflexão. Physis. 2008 [acesso em 2021 maio 21]; 18(2):251-275. Disponível em: https://doi.org/10.1590/S010373312008000200004. 
11. Loyola MA. Medicamentos e saúde pública em tempos de AIDS: metamorfoses de uma política dependente. Ciênc. Saúde Colet. 2008 [acesso em 2021 maio 21]; 13(supl):763-778. Disponível em: https:// doi.org/10.1590/S1413-81232008000700027.

12. Loyola MAR, organizadora. Aids e Sexualidade: $o$ ponto de vista das ciências humanas Rio de Janeiro: Relume-Dumará; UERJ;1994.

13. Loyola MAR, organizadora. A sexualidade nas Ciências Humanas. Rio de Janeiro: Eduerj; 1998.

14. Loyola MAR. Sexualidade e Reprodução. 1992 [acesso em 2020 ago 31]; 2(1):93-105. Disponível em: https://doi.org/10.1590/S0103-73311992000100004.

15. Loyola MAR, organizadora. Bioética, reprodução e gênero na sociedade contemporânea. Rio de Janeiro; Brasília, DF: ABEP; Letras Livres; 2005.
16. Corrêa MCDV, Loyola MA. Tecnologias de reprodução assistida no Brasil: opções para ampliar o acesso. Physis. 2015 [acesso em 2021 maio 21]; 25(3):753-777. Disponível em: https://doi.org/10.1590/ S0103-73312015000300005.

17. Corrêa MV, Loyola MA. Novas tecnologias reprodutivas: novas estratégias de reprodução? Physis. 1999 [acesso em 2021 maio 21]; 9(1):209-234. Disponível em: https://doi.org/10.1590/S0103-73311999000100009.

18. Loyola MAR. A interferência da família na medicina. In: Silva EFH, Barboza HH, Almeida V, organizadores: Biotecnologia e relações familiares. Rio de Janeiro: Processo; 2021.

Recebido em 01/09/2020

Aprovado em 25/05/2021

Conflito de interesses: inexistente

Suporte financeiro: não houve 